\title{
Diagnosis versus Ideological Diversity - Corrigendum
}

\section{Phillip W. Gray}

doi: https://doi.org/10.1017/S104909651900066o Published by Cambridge University Press, 11 June 2019.

The author and editors apologize sincerely for any perception by readers that the article insinuates any research dishonesty or misconduct on the part of Verhulst, Eaves, and Hatemi in relation to their paper "Correlation not Causation: The Relationship between Personality Traits and Political Ideologies" (Verhulst, Eaves, and Hatemi 2012). This was entirely unintended. The article has been corrected by re-casting the second sentence of paragraph two, to completely separate the LaCour fabrication from Verhulst, Eaves, and Hatemi's coding error. We wish to reiterate that the erratum to Verhulst, Eaves and Hatemi's work (Verhulst, Eaves, and Hatemi 2015) was issued to address a coding mistake, and not reflective of any dishonesty.

The author regrets this error. The original version has been updated.

\section{REFERENCES}

Gray, Phillip W. "Diagnosis versus Ideological Diversity.” PS: Political Science E Politics. Published online 11 June 2019. doi: https://doi.org/10.1017/S10490965190oo66o Verhulst, Brad, Lindon Eaves, and Peter K. Hatemi. 2012. "Correlation Not Causation: The Relationship between Personality Traits and Political Ideologies.” American Journal of Political Science 56 (1): 34-51.

Verhulst, Brad, Lindon Eaves, and Peter K. Hatemi. 2015. "Erratum to 'Correlation Not Causation: The Relationship between Personality Traits and Political Ideologies' American Journal of Political Science 56 (1): 34-51.” American Journal of Political Science 6o: E3-E4. Available at https://onlinelibrary.wiley.com/doi/full/10.1111/ajps.12216. Accessed October 29, 2018. 

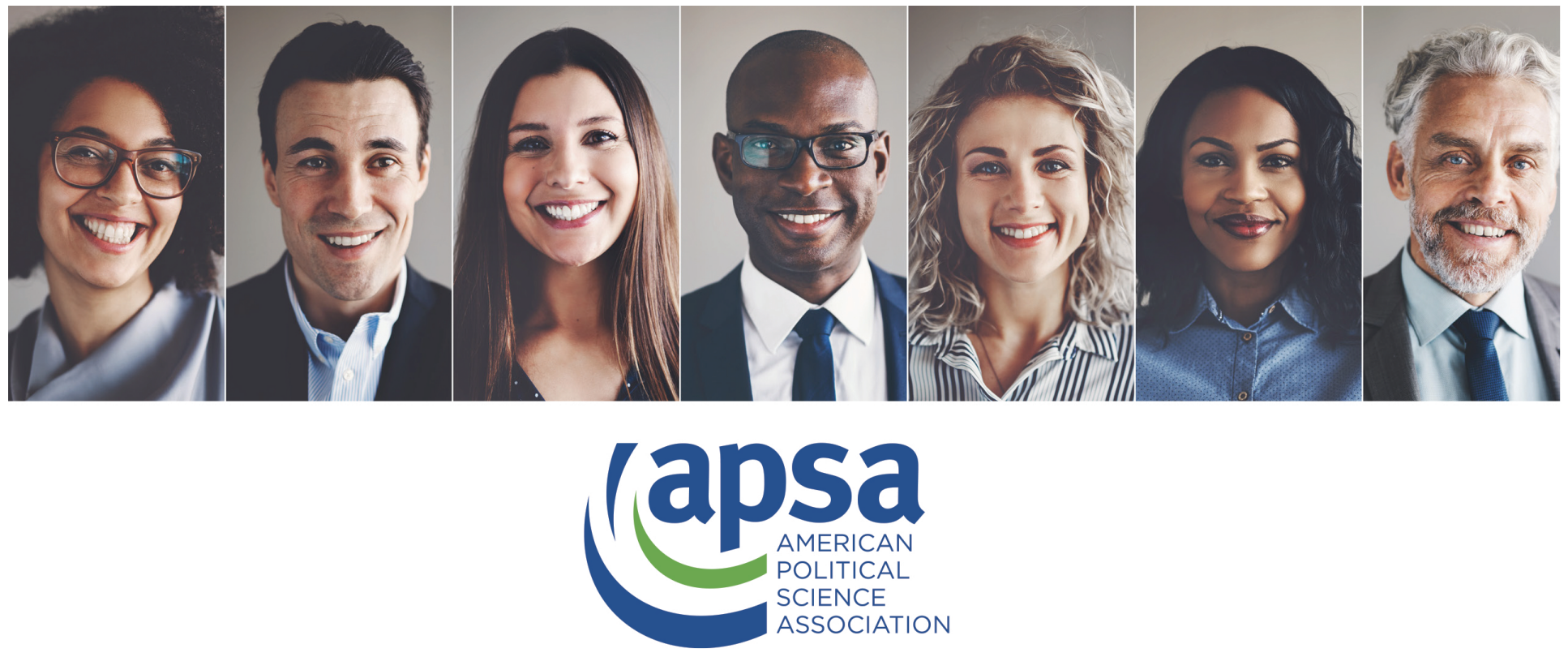

\section{Find a Mentor or Become a Mentor}

The APSA Mentoring Program is an opportunity for all political scientists to network and share experience, advice and insights about career planning, scholarship, and a variety of professional issues such as:

\section{- Selecting a dissertation committee}

- Publishing and research

- Non-academic careers

- Life as junior faculty member

- Balancing family and work

APSA seeks mentors that provide professional advice to undergraduates, graduate students, and junior faculty in the profession, specifically in non-academic careers and international relations, and to mentor Ralph Bunche Scholars (RBSI) and/or APSA Minority Fellows (MFP).

\section{Matching Process}

APSA accepts mentor requests for short-term (one semester) and long-term (one academic year) mentoring. However, matched mentors and mentees are encouraged to continue the relationship beyond the official APSA mentoring period if they find it mutually beneficial.

The APSA staff makes mentor matches twice a year: once at the beginning of the fall semester (for short term and long term matches) and once at the beginning of the spring semester (for short term matches). Matches are made first-come, first-served based on suitability of the match profile and mentor availability.

\section{Apply today! Submit an online application to become or request a mentor at www.apsanet.org/mentor.}

